\title{
Swiss Cantonal Banks: A DEA Efficiency and Productivity Analysis
}

\author{
Trishit Bandyopadhyay ${ }^{1}$, David Bobst ${ }^{2}$, Tobias Hummel ${ }^{2}$, Galia Kondova, ${ }^{2, *}$ \\ ${ }^{1}$ School of Advanced Management, XLRI - Xavier School of Management, Jharkhand, India \\ ${ }^{2}$ School of Business, FHNW University of Applied Sciences, Basel, Switzerland
}

Copyright $(\mathrm{C} 2018$ by authors, all rights reserved. Authors agree that this article remains permanently open access under the terms of the Creative Commons Attribution License 4.0 International License

\begin{abstract}
This paper applies a data envelopment analysis (DEA) to study the efficiency and productivity changes in the Swiss cantonal bank sector in the period 2006-2014. The efficiency analysis is conducted by applying the production input-oriented DEA variable returns to scale model in a three-stage procedure. The productivity is studied by estimating a DEA-based Malmquist Productivity Index (MPI) that provides evidence of increasing productivity growth on average for the sector in the studied period. The main source of productivity growth as per the components of the Banker, Charnes and Cooper (BCC) MPI model is related to a frontier-shift (technological innovation) rather than to improvements in the technical efficiency. The decreasing average DEA scores in the post-global financial crisis period of 2008-2014 further support this finding. In the second stage of the efficiency analysis, the environmental factors influencing the productivity growth are analysed by conducting a general method of moments (GMM) regression. The results provide evidence of a positive and statistically significant relationship between the stock of residential buildings per canton and technical efficiency. In the third stage, the environmental variables from the second-stage regression are included within the constraints of the first-stage DEA model as proposed by Ray [1]. The third-stage DEA scores support the evidence of slightly decreasing average post-global crisis technical efficiency. The overall average technical efficiency in the Swiss cantonal banking sector, however, remains at a relatively high level in the studied period.
\end{abstract}

Keywords Swiss Cantonal Banks, Data Envelopment Analysis, Bank Efficiency, Bank Productivity, Malmquist Productivity Index

\section{Introduction}

This paper is the first one, to the authors' knowledge, to study efficiency and productivity in the Swiss cantonal bank sector by using DEA efficiency scores and a DEA-based Malmquist Productivity Index. The importance of the studied sector is underpinned by the fact that it accounts for the largest market share of mortgage lending in Switzerland. Moreover, analysing the efficiency and productivity in the sector in the period 2006-2014 provides useful insights especially as to the impact of the global financial crisis of 2008 on the 24 cantonal banks in this sector. Improving efficiency and productivity is a goal associated with higher competitiveness and improved services to the clients. In this context, the findings of the paper should contribute to the public discussion on efficiency and productivity in the Swiss banking sector.

The paper uses the production input-oriented DEA variable returns to scale model to estimate technical efficiency scores for the 24 cantonal banks in a first-stage. In the second stage of the DEA model, the effects of environmental factors like stock of residential buildings, unemployment, and economy development on bank efficiency and productivity are analysed by applying the general method of moments (GMM). In particular, the authors apply the Arellano-Bond estimator rather than the widely used OLS or Tobit estimators, since it provides consistent estimates despite violations of the exogeneity condition. The influence of the second-stage environmental factors is then taken into consideration in the third stage by re-estimating the first-stage DEA model along the procedure proposed by Ray [1]. Finally, the productivity is analysed by applying the innovative method of DEA-based Malmquist Productivity Index for the cantonal banking sector that distinguishes between technical efficiency changes and technological changes.

\section{Literature Review}

The initial concept of DEA as a productivity and efficiency measurement tool is to be credited to the work of Farrell [2] which defined technical efficiency as the ability 
of a firm to obtain maximum feasible output from a given amount of inputs. Its application as a practical research tool though was facilitated by the development of the Charnes, Cooper and Rhodes (CCR) model [3] and the one of Banker, Charnes and Cooper (BCC) [4].

The CCR model assumes constant returns-to-scale (CRS) of the production function. The objective score of the CCR model is designated technical efficiency (TE). On the other hand, the $\mathrm{BCC}$ model is built on the assumption of variable returns-to-scale (VRS). The objective value of the BCC model is said to reflect pure technical efficiency.

Coelli [5] argues that the CRS assumption is appropriate only in case all units are operating at an optimal scale. In practice, there are usually factors such as imperfect competition, constraints to finance, etc. that lead to operation at suboptimal scale.

DEA uses a non-parametric mathematical linear programming approach. It gives a comparative ratio of weighted outputs to inputs for each decision-making unit (DMU). The relative score takes values between 0 and 1 ( 0 and $100 \%$ ). A score of less than 1 indicates inefficiency relative to the units on the efficient frontier of best performers [6].

DEA estimates a set of weights so that the ratio of weighted sums of the outputs and inputs as outlined in (1) is maximized for each unit:

$$
E=\frac{\sum_{j} w_{j} Y_{j}}{\sum_{i} v_{i} X_{i}}
$$

where $E$ denotes the efficiency score, $X_{\mathrm{i}}$ denotes inputs, $Y_{j}$ denotes outputs, $w_{j}$ denotes the output weights to be estimated, $v_{i}$ denotes the input weights to be estimated. DEA computes a separate set of weights for each bank, instead of using fixed weights for all units under evaluation. Weights are optimized to make each bank's score the best possible under the constraint that no bank's efficiency exceeds 1 when using the same weights.

According to the model specification, it is also possible to measure either input-oriented or output-oriented technical efficiency. As explained by Jacobs [7], the input-orientation implies keeping outputs fixed while exploring the proportional reduction in inputs. The output-orientation, on the other hand, explores the possible proportional increase of outputs while keeping inputs constant.

Considering the fact that there are factors that influence efficiency but are not direct inputs or outputs to the production process, the DEA-based efficiency analysis is expanded to incorporate the impact of these environmental factors. For example, Drake at al. [8] use a slacks-based, second stage Tobit regression approach to incorporate the environmental factors in the efficiency analysis. Ray [1] who includes the environmental variables within the constraints of the DEA model presents an alternative approach.
Furthermore, changes in productivity and efficiency could be measured by the calculation of the Malmquist productivity index (MPI) as introduced by Caves et al. [9] building on the work of Malmquist [10]. The estimation of the MPI by non-parametric techniques such as DEA was introduced by the work of Färe et al. [11]. The later work of Färe et al. [12] then provided an intuitive decomposition of efficiency into two mutually exclusive sources, namely into technical efficiency changes (EFFCH) or catch-up and technological change (TECH) or frontier-shift. Thus, this decomposition of the MPI could be represented by equation (2):

$$
M P I_{i t}=E F F C H_{i t} \times T E C H_{i t}
$$

where $M P I_{i t}$ is the Malmquist Productivity Index of $i^{\text {th }}$ DMU at time petiod $t, E F F C H_{i t}$ is the technical efficiency change of $i^{\text {th }}$ DMU at time period $t$, and $T E C H_{i t}$ is the technological change of $i^{\text {th }}$ DMU at time period $t$. Additional studies [13-14] have extended the decomposition and provided further analysis of the sources of growth.

The survey of Färe et al. [15] takes stock of empirical MPI studies that have used non-parametric techniques like DEA because of advantages such as its applicability in cases with insufficient degrees of freedom and the possibility to model production technology without predetermining its functional form. On the other hand side, it does not permit formal statistical hypotheses testing as in studies applying a parametric approach such as a stochastic frontier [16].

\section{Methodology}

\subsection{First-stage DEA Input-oriented BCC Production Model}

Following the relevant literature on DEA efficiency in banking $[17,18]$, this study identifies the production-oriented $\mathrm{BCC}$ input DEA model as the most appropriate one for the efficiency analysis in the Swiss cantonal bank sector. The respective input and output variables, as outlined in Table 1, comprise of Number of Employees and Operational Costs as input variables and Deposits and Loans as output Variables.

Table 1. Input and Output Variables

\begin{tabular}{|c|c|}
\hline Input Variables & Output Variables \\
\hline Number of Employees & Deposits \\
\hline Operational Costs & Loans \\
\hline
\end{tabular}

Cantonal banks are retail banks and they successfully apply the model of relationship banking to support the prosperity of the respective local communities. As such, their business model focuses on deposit raising and credit allocation to the local business and citizens. Therefore, 
their major products or "outputs" in the terminology of DEA can be identified as deposits and loans. On the other hand, the major costs or "inputs" are associated with the number of employees and the operational expenses (expenses for material, building rent, etc.) used to produce the outlined outputs. Investment banking activities and profit-maximization are not the focus of the mandate pursued by the cantonal banks. Considering these facts, the production approach with the mentioned input/output variables rather than profitability or intermediation approach is identified as the most appropriate model to be applied for the analysis.

Moreover, the fact that the cantonal banks have a regional focus of activities and, with a few exceptions, are not active across cantons or internationally, explains the objective limitations of the output volumes. Therefore, an input-orientation is a further specification to the DEA model.

Finally, as discussed in the previous part, the BCC VRS model is considered superior to the CRS DEA model.

\subsection{Second-stage General Method of Moments (GMM) Regressional Analysis of Environmental Factors}

The bank-external factors, the environmental variables, that might influence the efficiency and are not included as inputs are studied by a GMM regressional analysis. Taking into consideration the findings of relevant empirical studies like the one of Drake et al. [19], we use variables such as the stock of residential buildings built in the respective canton in each of the period years, the annual GDP per capita and the annual unemployment rate for each canton as relevant environmental variables.

We conduct a regressional analysis by using a general method of moments (GMM) estimator such as the Arellano-Bond one [20] that provides consistent estimates despite violations of the exogeneity condition due to the interdependency between some of the environmental factors and the DEA inputs/outputs.

\subsection{Third-stage DEA Model Accounting for Environmental Variables}

The authors apply an extension of the first-stage DEA model as proposed by Ray [1] to account for the environmental variables studied in the second stage. In particular, Ray [1] proposes to include the nondiscretionary (environmental) variables "within the constraints but not in the objective function of the DEA model" in order to incorporate the environmental factors directly in the DEA model. Moreover, the authors include within the model constraints only the statistically significant variables in the GMM regression, namely the stock of residential buildings per canton. In addition, the positive sign in front of the residential buildings variable classifies it as a favorable factor within the constraints specification of the extended DEA model.

\subsection{DEA-based Malmquist Productivity Index}

In order to closer study the changes in efficiency, the DEA-based Malmquist Productivity Index (MPI) is calculated for the sample and the studied period. The MPI measures the annual productivity change (growth or decline) for each bank in the sample. Furthermore, the MPI is decomposed for each bank into the two mutually exclusive components, one measuring change in technical efficiency (catching-up effect) and the other measuring change in technology (innovation). The efficiency component of the index measures changes in technical efficiency from period $t$ to period $t+1$. That measures how the units being examined have managed to catch up to the frontier. On the other hand, the technical component of the index measures changes in the production frontier (i.e. a shift in best-practice technology) from period $t$ to period $t+$ 1 [21]. Improvements in productivity result in Malmquist index values greater than unity. Deterioration in performance over time is associated with a Malmquist index less than unity.

\section{Data}

The 24 cantonal banks in the Swiss banking sector accounted for the largest market share of mortgage lending as of end-2013, namely, 35\% of total banking sector mortgages [22]. At the same time, the deposit base of the cantonal banks experienced a steady increase in the studied period 2006-2014 and especially after the Global Financial Crisis of 2007-2008 [23]. Figure 1 shows these developments:

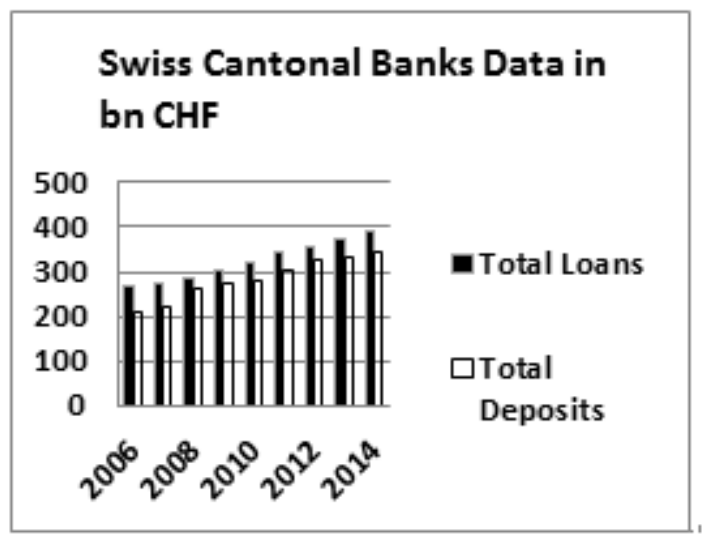

Figure 1. Swiss cantonal banks total deposits and mortgage loans 2006-2014, SNB (2015)

The data for the analysis was obtained from publications of the Swiss Association of Cantonal Banks and the Swiss National Bank. The dataset covers all 24 Swiss cantonal banks and includes the operational expenses, number of employees, deposits and loans per 
bank on an annual basis for the period 2006-2014. In addition, data published by the Swiss Statistics Office on annual residential housing buildings per canton, the annual GDP per capita in Switzerland and the annual unemployment rate per canton for the period 2006-2014 is used in the analysis.

\section{Results}

\subsection{First Stage: DEA Efficiency Scores on the Input-oriented BCC Production Model}

The DEA technical efficiency scores on the 24 Swiss cantonal banks calculated by applying the input-oriented BCC production approach are listed in Table 2 below. In general, the average technical efficiency score of 0.852 for the cantonal bank sector in the studied period provides a preliminary evidence of a relative high efficiency in the sector in general. The annual average scores between 2006 and 2014 vary in the range between 0.860 and 0.899 . In the post-global financial crisis period of 2008-2014, the average DEA scores have been gradually decreasing from 0.888 to 0.865 with the exception of 2012 when the average score dropped sharply to 0.660 .

The sharp decrease of the average efficiency sore for the whole banking group in 2012 is linked to the activation of the countercyclical capital buffer in Switzerland in July 2012, which resulted in a reduction of capital available for lending. Moreover, Auer et al. [24] found out a positive relationship between the enabling of the activation of the countercyclical capital buffer in Switzerland in July 2012 and the cost of lending to corporations.

Since important environmental factors have a significant influence on efficiency as demonstrated in the case of the activation of the countercyclical capital buffer in Switzerland in 2012, while at the same time, these factors are not included as inputs in the DEA models, we study the effect of such factors on technical efficiency by a GMM regressional analysis that follows.

Table 2. DEA production approach efficiency scores on the 24 Swiss cantonal banks in the period 2006-2014

\begin{tabular}{|c|c|c|c|c|c|c|c|c|c|c|}
\hline DMU (Bank) & 2006 & 2007 & 2008 & 2009 & 2010 & 2011 & 2012 & 2013 & 2014 & Average \\
\hline 1 & 1.000 & 1.000 & 1.000 & 1.000 & 0.954 & 0.888 & 0.657 & 0.852 & 0.879 & 0.914 \\
\hline 2 & 1.000 & 1.000 & 1.000 & 1.000 & 1.000 & 1.000 & 0.874 & 1.000 & 1.000 & 0.986 \\
\hline 3 & 0.896 & 0.893 & 0.926 & 1.000 & 0.883 & 0.883 & 0.677 & 0.824 & 0.933 & 0.879 \\
\hline 4 & 0.945 & 0.958 & 0.915 & 0.926 & 1.000 & 1.000 & 0.588 & 0.855 & 0.889 & 0.897 \\
\hline 5 & 1.000 & 1.000 & 1.000 & 0.985 & 0.527 & 0.893 & 0.586 & 0.882 & 0.898 & 0.863 \\
\hline 6 & 1.000 & 1.000 & 1.000 & 1.000 & 0.806 & 1.000 & 1.000 & 1.000 & 1.000 & 0.978 \\
\hline 7 & 0.625 & 0.598 & 0.578 & 0.569 & 0.726 & 0.541 & 0.501 & 0.526 & 0.516 & 0.576 \\
\hline 8 & 0.876 & 0.876 & 0.796 & 0.782 & 0.865 & 0.737 & 0.547 & 0.750 & 0.786 & 0.779 \\
\hline 9 & 0.784 & 0.894 & 0.831 & 0.732 & 1.000 & 0.698 & 0.625 & 0.789 & 0.805 & 0.795 \\
\hline 10 & 0.726 & 0.761 & 0.712 & 0.726 & 0.827 & 0.886 & 0.495 & 0.889 & 0.863 & 0.765 \\
\hline 11 & 1.000 & 1.000 & 1.000 & 1.000 & 0.802 & 1.000 & 0.716 & 1.000 & 1.000 & 0.946 \\
\hline 12 & 0.746 & 0.723 & 0.767 & 0.809 & 0.997 & 0.817 & 0.716 & 0.843 & 0.909 & 0.814 \\
\hline 13 & 0.911 & 0.907 & 0.843 & 0.850 & 0.886 & 0.870 & 0.728 & 0.792 & 0.795 & 0.842 \\
\hline 14 & 1.000 & 1.000 & 1.000 & 0.907 & 0.845 & 0.999 & 0.697 & 1.000 & 1.000 & 0.939 \\
\hline 15 & 0.962 & 0.891 & 0.859 & 0.869 & 0.918 & 0.869 & 0.565 & 0.798 & 0.815 & 0.839 \\
\hline 16 & 0.817 & 0.911 & 0.896 & 0.863 & 0.573 & 0.850 & 0.676 & 0.938 & 0.939 & 0.829 \\
\hline 17 & 1.000 & 1.000 & 1.000 & 0.870 & 0.939 & 0.889 & 0.817 & 0.985 & 1.000 & 0.945 \\
\hline 18 & 0.725 & 0.679 & 0.728 & 0.674 & 1.000 & 0.594 & 0.552 & 0.680 & 0.632 & 0.696 \\
\hline 19 & 1.000 & 0.963 & 0.963 & 0.985 & 0.842 & 0.851 & 0.649 & 0.725 & 0.663 & 0.849 \\
\hline 20 & 0.931 & 1.000 & 1.000 & 1.000 & 0.753 & 1.000 & 0.629 & 1.000 & 1.000 & 0.924 \\
\hline 21 & 0.956 & 0.841 & 0.886 & 0.854 & 0.799 & 0.884 & 0.833 & 0.968 & 0.881 & 0.878 \\
\hline 22 & 0.661 & 0.806 & 0.762 & 0.789 & 1.000 & 0.737 & 0.462 & 0.721 & 0.756 & 0.744 \\
\hline 23 & 0.931 & 0.886 & 0.863 & 0.828 & 0.888 & 0.781 & 0.729 & 0.823 & 0.792 & 0.836 \\
\hline 24 & 1.000 & 1.000 & 1.000 & 1.000 & 1.000 & 1.000 & 0.525 & 1.000 & 1.000 & 0.947 \\
\hline Average & 0.895 & 0.899 & 0.888 & 0.876 & 0.868 & 0.861 & 0.660 & 0.860 & 0.865 & 0.852 \\
\hline
\end{tabular}

\subsection{Second Stage: GMM Regressional Analysis of Environmental Factors}

Consistent with the literature on environmental factors in efficiency analyses $[25,8]$, we use the following environmental variables: the annual number of stock of residential buildings per canton (Haus), the annual GDP per capita and canton $(G D P p c)$, and the annual unemployment rate per canton (Unempl Rate) as independent variables in a GMM regressional analysis using the one-step Arellano- Bond estimator [20] for the pooled data in Table 2 for the period 2006-2014. We focus mainly on the macroeconomic environmental factors since these are believed to have the greatest 
impact on business activities after the global financial crisis of 2007/2008. As a dependent variable, we use the natural logarithm of the annual pooled DEA efficiency scores. Table 3 shows the GMM results.

Table 3. Arellano-Bond estimates of environmental factors

\begin{tabular}{|c|c|c|c|c|c|c|}
\hline & & Robust & & & & \\
\hline LnVrseff & Coef. & std. Err. & $z$ & $P>|z|$ & [95\% Conf. & Interval] \\
\hline \multicolumn{7}{|l|}{ LnVrseff } \\
\hline L1. & .9309891 & .2942742 & 3.16 & 0.002 & .3542223 & 1.507756 \\
\hline Haus & .000034 & .0000168 & 2.03 & 0.043 & $1.12 e-06$ & .0000669 \\
\hline GDPpc & $-1.55 e-06$ & $2.12 e-06$ & -0.73 & 0.465 & $-5.71 e-06$ & $2.61 e-06$ \\
\hline UnEmplRate & -.0048323 & .0263232 & -0.18 & 0.854 & -.0564249 & .0467603 \\
\hline
\end{tabular}

It could be seen from Table 3 that the variable stock of residential buildings per capita and canton (Haus) has a positive and statistically significant effect on the efficiency score. The other two variables are statistically insignificant with $p$-values greater than $5 \%$.

\subsection{Third Stage: DEA Model with Environmental Variables as Model Constraints}

The first-stage DEA model is modified as per the method suggested by Ray [1] by including the relevant environmental variables with the constraints of the model. In our case, the only statistically significant environmental variable in the GMM second-stage regressional estimation is annual stock of residential buildings per canton (Haus). Moreover, it has a positive impact on the efficiency scores. Therefore, it is treated as a favorable factor and included within the constraints of the first-stage input-oriented DEA model. The calculated adjusted DEA scores are outlined in Table 4.

Table 4. DEA scores adjusted for environmental effects

\begin{tabular}{|c|c|c|c|c|c|c|c|c|c|c|}
\hline DMU (Bank) & 2006 & 2007 & 2008 & 2009 & 2010 & 2011 & 2012 & 2013 & 2014 & Average \\
\hline 1 & 1.000 & 1.000 & 1.000 & 1.000 & 0.967 & 0.888 & 0.844 & 0.852 & 0.879 & 0.937 \\
\hline 2 & 1.000 & 1.000 & 1.000 & 1.000 & 1.000 & 0.859 & 1.000 & 1.000 & 1.000 & 0.984 \\
\hline 3 & 0.989 & 1.000 & 0.949 & 1.000 & 0.954 & 0.883 & 0.817 & 0.824 & 0.946 & 0.929 \\
\hline 4 & 1.000 & 1.000 & 1.000 & 1.000 & 1.000 & 1.000 & 1.000 & 1.000 & 1.000 & 1.000 \\
\hline 5 & 1.000 & 1.000 & 1.000 & 0.985 & 0.883 & 0.893 & 0.875 & 0.882 & 0.898 & 0.935 \\
\hline 6 & 1.000 & 1.000 & 1.000 & 1.000 & 1.000 & 1.000 & 1.000 & 1.000 & 1.000 & 1.000 \\
\hline 7 & 0.737 & 0.706 & 0.661 & 0.669 & 0.631 & 0.670 & 0.629 & 0.655 & 0.641 & 0.667 \\
\hline 8 & 0.945 & 0.924 & 0.888 & 0.863 & 0.877 & 0.596 & 0.765 & 0.806 & 0.817 & 0.831 \\
\hline 9 & 0.784 & 0.894 & 0.831 & 0.733 & 0.738 & 0.708 & 0.734 & 0.792 & 0.805 & 0.780 \\
\hline 10 & 0.726 & 0.761 & 0.712 & 0.726 & 0.865 & 0.517 & 0.883 & 0.889 & 0.863 & 0.771 \\
\hline 11 & 1.000 & 1.000 & 1.000 & 1.000 & 1.000 & 1.000 & 1.000 & 1.000 & 1.000 & 1.000 \\
\hline 12 & 0.755 & 0.723 & 0.776 & 0.861 & 0.868 & 0.806 & 0.850 & 0.866 & 0.930 & 0.826 \\
\hline 13 & 1.000 & 1.000 & 1.000 & 1.000 & 1.000 & 0.952 & 1.000 & 1.000 & 1.000 & 0.995 \\
\hline 14 & 1.000 & 1.000 & 1.000 & 1.000 & 1.000 & 0.918 & 1.000 & 1.000 & 1.000 & 0.991 \\
\hline 15 & 0.969 & 0.908 & 0.872 & 0.869 & 0.886 & 0.869 & 0.828 & 0.798 & 0.815 & 0.868 \\
\hline 16 & 0.826 & 0.911 & 0.896 & 0.898 & 0.857 & 0.744 & 0.871 & 0.938 & 0.939 & 0.876 \\
\hline 17 & 1.000 & 1.000 & 1.000 & 1.000 & 1.000 & 1.000 & 1.000 & 1.000 & 1.000 & 1.000 \\
\hline 18 & 0.725 & 0.679 & 0.728 & 0.674 & 0.573 & 0.553 & 0.602 & 0.680 & 0.632 & 0.650 \\
\hline 19 & 1.000 & 1.000 & 1.000 & 1.000 & 0.966 & 0.886 & 0.817 & 0.768 & 0.719 & 0.906 \\
\hline 20 & 1.000 & 1.000 & 1.000 & 1.000 & 1.000 & 0.703 & 1.000 & 1.000 & 1.000 & 0.967 \\
\hline 21 & 0.956 & 0.841 & 0.886 & 0.854 & 0.842 & 0.862 & 0.857 & 0.968 & 0.881 & 0.883 \\
\hline 22 & 0.667 & 0.831 & 0.764 & 0.789 & 0.753 & 0.737 & 0.744 & 0.721 & 0.756 & 0.751 \\
\hline 23 & 1.000 & 1.000 & 1.000 & 1.000 & 1.000 & 1.000 & 1.000 & 1.000 & 1.000 & 1.000 \\
\hline 24 & 1.000 & 1.000 & 1.000 & 1.000 & 1.000 & 1.000 & 1.000 & 1.000 & 1.000 & 1.000 \\
\hline Average & 0.920 & 0.924 & 0.915 & 0.913 & 0.903 & 0.835 & 0.880 & 0.893 & 0.897 & 0.898 \\
\hline
\end{tabular}


The DEA adjusted scores in Table 4 are higher on average than the first-stage DEA scores reflecting the favorable factor included in the model constraints. The annual average values of the adjusted scores vary between 0.924 and 0.835 with an average of 0.898 . Similar to the first stage results, the DEA adjusted scores also decrease slightly in the years after the global financial crisis of 2008 but then stabilize and start improving towards the end of the studied period.

\subsection{DEA-based Input-oriented MPI}

As already outlined, the DEA technical efficiency scores do not provide any insight as to changes in productivity and, in particular, as to any possible frontier-shifts. Therefore, a Malmquist Productivity Index is being calculated as a next step of the analysis by using the already calculated DEA technical efficiency scores as inputs. Table 5 shows the annual productivity changes for each bank measured by the input-oriented MPI. Annual growth in productivity, i.e. MPI values greater than 1 , is denoted with the abbreviation "incr", annual decrease with "decr" and no change with "same". The number of all banks that have experienced increase, respectively decrease or no change of the $M P I$, is being denoted by $N$ "incr", respectively $N$ "same" and $N$ "decr".
As could be seen in Table 5, the sum of annual improvements in productivity (151) far exceeds the total number of annual productivity deteriorations (18) over the studied period. The number of cases where there was no annual productivity change amounts to 23 .

So the positive average developments registered in Table 5 provide evidence that the overall productivity has been improving for the sector in general. The results of the decomposition of the MPI into technical efficiency $(E F F C H)$ and technological change $(T E C H)$ are shown in Tables 6 and Table 7.

The results in Table 6 show that the number of banks with an annual decrease or no change in productivity due to technical efficiency far outweigh the number of cases with an annual increase of productivity due to technical efficiency. This result already gives an indication that the overall productivity growth over the studied period is rather not due to the catch-up effect such as managerial efficiency. The overall productivity growth is rather due to a frontier-shift as demonstrated by the results in Table 7 where the number of banks that experienced an annual increase of productivity due to technological change (62) outweighs the ones that experienced an annual decrease (only 5). The rest of the observations experience the same level of productivity.

Table 5. Input-oriented DEA-based MPI results - number of banks with respective MPI annual values

\begin{tabular}{|c|c|c|c|c|c|c|c|c|}
\hline & MPI0607 & MPI0708 & MPI0809 & MPI0910 & MPI1011 & MPI1112 & MPI1213 & MPI1314 \\
\hline N"incr" & 16 & 17 & 17 & 18 & 23 & 21 & 19 & 20 \\
\hline N"same" & 4 & 3 & 5 & 3 & 0 & 3 & 3 & 2 \\
\hline N"decr" & 4 & 4 & 2 & 3 & 1 & 0 & 2 & 2 \\
\hline
\end{tabular}

N"incr" denotes the number of banks with a MPI value higher than one, N"same" denotes the number of banks with a MPI value of one, N"decr" denotes the number of banks with a MPI value of less than one.

MPI0607 (to MPI1314) denotes the respective two consecutive years for which the respective annual change has been calculated.

Table 6. MPI technical efficiency measure - number of banks with respective MPI annual values

\begin{tabular}{|c|c|c|c|c|c|c|c|c|}
\hline & EFFCH0607 & EFFCH0708 & EFFCH0809 & EFFCH0910 & EFFCH1011 & EFFCH1112 & EFFCH1213 & EFFCH1314 \\
\hline N“incr” & 1 & 7 & 2 & 0 & 0 & 0 & 5 & 0 \\
\hline N"same” & 13 & 17 & 17 & 23 & 22 & 22 & 19 & 22 \\
\hline N"decr” & 10 & 0 & 5 & 1 & 2 & 2 & 0 & 2 \\
\hline
\end{tabular}

N"incr" denotes the number of banks with an EFFCH value higher than one, N"same" denotes the number of banks with an EFFCH value of one, N"decr" denotes the number of banks with an EFFCH value of less than one.

MPI0607 (to MPI1314) denotes the respective two consecutive years for which the respective annual change has been calculated.

Table 7. MPI technological change measure - number of banks with respective MPI annual changes

\begin{tabular}{|c|c|c|c|c|c|c|c|c|}
\hline & TECH0607 & TECH0708 & TECH0809 & TECH0910 & TECH1011 & TECH1112 & TECH1213 & TECH1314 \\
\hline N“incr” & 13 & 0 & 10 & 1 & 16 & 22 & 0 & 0 \\
\hline N"same” & 11 & 19 & 14 & 23 & 8 & 2 & 24 & 24 \\
\hline N"decr” & 0 & 5 & 0 & 0 & 0 & 0 & 0 & 0 \\
\hline
\end{tabular}

N"incr" denotes the number of banks with a TECH value higher than one, N"same" denotes the number of banks with a TECH value of one, N"decr" denotes the number of banks with a TECH value of less than one.

MPI0607 (to MPI1314) denotes the respective two consecutive years for which the respective annual change has been calculated. 


\section{Discussion and Conclusions}

This paper studies the efficiency and productivity developments among the 24 Swiss cantonal banks in the period 2006-2014 by applying the input-based variable returns to scale production DEA model with number of employees and operational costs as the model inputs, total deposits and loans as the model outputs and the number of annual stock of residential buildings per canton as a favorable factor in the model constraints. The favorable factor is included in the constraints of the model after being the only statistically significant variable in the GMM regression on the environmental variables.

Our first-stage DEA technical efficiency scores of the studied 24 Swiss cantonal banks in the period 2006-2014 are within the range of 0.899 and 0.852 with a one-year drop to 0.660 in 2012 . There is a slight decrease in average efficiency after the post-global financial crisis. However, average efficiency of the sector stays at a relatively high level. The 2012 sharp drop is associated with the activation of the countercyclical capital buffer in Switzerland in July 2012, which resulted in a reduction of capital available for lending.

Moreover, the DEA scores adjusted for annual stock of residential buildings per canton are higher on average than the first-stage DEA scores. They vary between 0.924 and 0.835 with an average of 0.898 . The DEA adjusted scores also decrease slightly in the years after the global financial crisis of 2008 but stabilize and start improving towards the end of the studied period.

We study the sources of annual changes in efficiency and productivity by calculating a DEA-based inputoriented MPI and its decomposition of technical efficiency and technological change. We find evidence of increasing productivity growth on average for the sector in the studied period. The main source of productivity growth is related to a frontier-shift (technological innovation) rather than to improvements in the technical efficiency. The shift is attributed to factors such as the advancing process of digitalization in banking and technological innovations in general.

We conclude that in the period 2006-2014, the Swiss cantonal banks have experienced productivity growth on average mainly due to a frontier shift rather than technical efficiency improvement. In fact, technical efficiency experienced a slight decrease in the first three years after the global financial crisis of 2008 but then stabilized and started slightly improving towards the end of the studied period. In general, the Swiss cantonal bank sector demonstrates a relatively high level of average technical efficiency being estimated at 0.898 under the third-stage DEA model for the studied period. Moreover, the sector has successfully overcome the slight decrease in technical efficiency after the global financial crisis of 2008.

\section{REFERENCES}

[1] S. Ray. Data Envelopment Analysis: Theory and Techniques for Economics and Operations Research. Cambridge University Press, 2004.

[2] M.J. Farrell. The Measurement of Productive Efficiency. Journal of the Royal Statistical Society, Series A, Vol. 120, No. 3, 253-290, 1957.

[3] A. Charnes, W.W. Cooper, E. Rhodes. Measuring the efficiency of decision-making units. European Journal of Operational Research, Vol. 2, No. 6, 429-444, 1978.

[4] R. Banker, A. Charnes, W.W. Cooper. Some models for estimating technical and scale inefficiencies in Data Envelopment Analysis. Management Science, Vol. 30, No. 9, 1078-1092, 1984.

[5] T.J. Coelli. A Guide to DEAP Version 2.1: Data Envelopment Analysis (Computer) Program, Working Paper 96/08, Centre for Efficiency and Productivity Analysis (CEPA), University of New England, 1996.

[6] C. A. F. Amado, S.P. Santos, P. Marques. Integrating the Data Envelopment Analysis and the Balanced Scorecard approaches for enhanced performance assessment. Omega, The International Journal of Management Science, Vol. 40, No. 3, 390-403, 2012.

[7] R. Jacobs, P. C. Smith, A. Street. Measuring efficiency in health care: analytic techniques and health policy. Cambridge University Press, 2006.

[8] L. Drake, M. J. B. Hall, R. Simper. The impact of macroeconomic and regulatory factors on bank efficiency: A non-parametric analysis of Hong Kong's banking system. Journal of Banking and Finance, Vol. 30, 1443-1446, 2006.

[9] D. W. Caves, L.R. Christensen, W. Diewert. The Economic Theory of Index Numbers and the Measurement of Input, Output, and Productivity. Econometrica, Vol. 50, No. 6, 1393-1414. 1982.

[10] S. Malmquist. Index Numbers and Indifference Surfaces. Trabajos de Estatistica, No. 4, 209-242, 1953.

[11] R. Färe, S. Grosskopf, B. Lindgren, P. Roos. Productivity Developments in Swedish Hospitals. Discussion Paper 89-3, Department of Economics, Southern Illinois University, Carbondale, 1989.

[12] R. Färe, S. Grosskopf. Malmquist Productivity Indexes and Fisher Ideal Indexes. Economic Journal. Vol. 102, No. 410, 158-160, 1992

[13] C. A. K. Lovell. The Decomposition of Malmquist Productivity Indexes. Journal of Productivity Analysis, Vol. 20, No. 3, 437-458, 2003.

[14] S. Grosskopf. Some Remarks on Productivity and its Decompositions. Journal of Productivity Analysis, Vol. 20, No. 3, 459-474, 2003.

[15] R. Färe, S. Grosskopf, P. Roos. Malmquist Productivity Indexes: A Survey of Theory and Practice. In: Färe R., Grosskopf S., Russell R.R. (eds) Index Numbers: Essays in Honour of Sten Malmquist. Springer, Dordrecht, 1998.

[16] M. Rossi. Technical change and efficiency measures: The post-privatization in the gas distribution sector in Argentina. 
Energy Economics, Vol. 23, 293-305, 2001.

[17] J. C. Paradi, S. Rouatt, H. Zhu. Two-stage evaluation of bank branch efficiency using data envelopment analysis. Omega, Vol. 39, 99-109, 2011.

[18] N. Avkiran. An Application Reference for Data Envelopment Analysis in Branch Banking: helping the novice researcher. International Journal of Bank Marketing, Vol. 17, No. 5, 206-220, 1999.

[19] L. Drake, M. J. B. Hall, R. Simper. The impact of macroeconomic and regulatory factors on bank efficiency: A non-parametric analysis of Hong Kong's banking system. Journal of Banking and Finance, Vol. 30, 1443-1446, 2006.

[20] M. Arellano, S. Bond. Some tests of specification for panel data: Monte Carlo evidence and an application to employment equations. The Review of Economic Studies, Vol. 58, No. 2, 277, 1991.
[21] D. W. Caves, L.R. Christensen, W. Diewert. The Economic Theory of Index Numbers and the Measurement of Input, Output, and Productivity. Econometrica, Vol. 50, No. 6, 1393-1414. 1982.

[22] Swiss National Bank. Bank Statistics 2014. Online available: https://www.snb.ch/en/mmr/reference/banks_2014/source/b anks_2014.en.pdf

[23] Swiss National Bank. Annual Banking Statistics 2015. Online available:

https://data.snb.ch/en/warehouse/BSTA\#!/facets

[24] R. Auer, S. Ongena. The Countercyclical Capital Buffer and the Composition of Bank Lending. BIS Working Paper No. 593, 2006. Online Available: https://www.bis.org/publ/work593.pdf

[25] K. Tone. A slacks-based measure of efficiency in data envelopment analysis. European Journal of Operational Research, Vol. 130, No. 3, 498-509, 2001. 